\title{
SEROEPIDEMIOLOGY OF VARICELLA AND VALUE OF SELF-REPORTED HISTORY OF VARICELLA INFECTION IN IRANIAN MEDICAL STUDENTS
}

\author{
ABBAS ALLAMI ${ }^{1}$, NAVID MOHAMMADI ${ }^{2}$, and AZADE NAJAR ${ }^{3}$ \\ ${ }^{1}$ Qazvin University of Medical Sciences, Qazvin, Iran \\ Department of Infectious Diseases, Faculty of Medicine \\ ${ }^{2}$ Iran University of Medical Sciences, Tehran, Iran \\ Department of Community Medicine, Faculty of Medicine \\ ${ }^{3}$ Qazvin University of Medical Sciences, Qazvin, Iran \\ Department of General Medicine
}

\begin{abstract}
Objectives: We conducted this study to assess the seroprevalence of Varicella zoster virus (VZV) antibodies in a group of Iranian medical sciences students that were at risk of Varicella and the value of self-reported history as a predictor of immunity. Material and Methods: 255 medical, nursing and obstetrics students who had not entered as a student or worked in a hospital from 3 different schools were enrolled in the study in 2012 (Qazvin province, Iran). Demographics and other information as well as the history of Varicella were obtained through a self-administered questionnaire. Blood samples were collected to determine the Varicella IgG levels via an enzyme-linked immunosorbent assay. A statistical analysis was performed by calculating prevalences and their 95\% confidence intervals. Sensitivity, specificity, positive and negative predictive values, Cohen's kappa and positive and negative likelihood ratios of recalled history were determined. $p<0.05$ was considered statistically significant. Results: The mean age of participants was $21.3 \pm 4.3$ years. Seropositivity rate was $74.5 \%$. The relationships between marital status, number of family members, and acquired VZV history with immunity against the virus were statistically significant. The overall rate of reported history was $57 \%$. The positive and negative predictive values of self-reported history of Varicella were $91 \%$ and $47.3 \%$, respectively. Conclusions: Immunization of students of Iranian medical sciences seems logical in the near future. Also, they should be tested for Varicella immunity regardless of the history of previous infection.
\end{abstract}

Key words:

Varicella, Medical student, Seroepidemiologic study

\section{INTRODUCTION}

Chickenpox or Varicella is a common acute viral childhood infection around the world. It is extremely contagious and characterized by a generalized exanthematous rash, as well as a relatively long period of morbidity lasting up to two weeks [1]. In immunocompetent patients, Varicella is usually benign and self-limited, although it can be more severe in adults. For the normal unimmunized children, chickenpox-associated mortality is less than two per 100 000. This risk increases by more than 15 -fold for adults [2]. General symptoms and skin lesions are more problematic and complications (e.g., pneumonia, encephalitis and hepatitis) are more often fatal in adults and adolescents $[3,4]$. 
Despite benign nature in healthy individuals, Varicella can result in substantial loss of productivity and is not a totally harmless disease, especially for people at risk (e.g., immunocompromised patients, premature infants, and newborns of seronegative mothers) [2]. Varicella is associated with a risk of virus transmission to the fetus or newborn and causes either congenital Varicella syndrome, herpes zoster during infancy/early childhood, or severe neonatal Varicella (depending on the gestational age) [5]. In health care setting, Varicella is an occupational hazard for those adults who did not acquire Varicella in childhood [6]. The highest risk concerns nurses and other medical personnel that provide care to infected people [7]. Until recently, in Iran, vaccination of children and susceptible health care workers (HCWs) has not been done due to the lack of a generally available vaccine (mostly because of problems with stability and cost). Information on seroprevalence of Varicella among students of medical sciences is important for developing vaccination programs or other strategies (to minimize its health care and economic impact). There are several international surveys on seroepidemiology of Varicella in health care workers [7,8-10]. While we have some epidemiological reports on Varicella in Iranian adults [11-17], only two studies have been conducted to find out the prevalence of Varicella immunity and the value of self-reported history of infection in medical students $[18,19]$. Therefore, this study aimed to determine the seroprevalence of Varicella zoster virus (VZV) antibodies as well as the value of self-reported history of infection in the students' subpopulation.

\section{MATERIAL AND METHODS}

\section{Study setting and participants}

Two hundred and seventy medical, nursing and obstetrics students from 3 different schools of Qazvin University of Medical Sciences (QUMS) enrolled in a cross sectional seroprevalence study of VZV antibodies ( $\operatorname{IgG})$ in 2012 (Qazvin province, Iran). The students were selected according to the date of their enrollment to the university and mostly came from the first and second year of studies. The participants had never entered as a student or worked in a hospital. They were asked to fill in a questionnaire (including questions on demographics, past history of chickenpox, family size, discipline of study and smoking status) and return it. Also, we had an interview with the participants for clarifying the answers. An informed consent was obtained from all students after a detailed explanation of the project. The study received approval from the Ethical Board of the Qazvin University of Medical Sciences.

\section{Laboratory data gathering and analysis}

A blood sample was obtained from each participant. Serum was separated and stored at $-20^{\circ} \mathrm{C}$. Then, the level of anti-VZV was measured by ELISA test anti-VZV/IgG (EUROIMMUN, Medizinische Labordiagnostika AG, Germany). Based on the manufacturer's manual, sensitivity and specificity of the test were $100 \%$ in detecting antibodies. It also mentioned that antibody levels equaling less than $8 \mathrm{U} / \mathrm{ml}, 8-12 \mathrm{U} / \mathrm{ml}$ and more than $>12 \mathrm{U} / \mathrm{ml}$ were considered negative, equivocal and positive, respectively. Positive results were considered as previous infection and immunization against VZV. Also, the data from the questionnaire and serological survey were analyzed to determine history of Varicella and seropositivity among 3 student groups. It is recommended to consider uncertain history of Varicella as negative in the occupational health care setting, so we added unknown histories to the negative history category [16].

\section{Statistical analysis}

Analyses were performed to determine the differences among three student groups using $\mathrm{Chi}^{2}$ tests and analysis of variance (ANOVA). Averages are presented, with p-values and/or $95 \%$ confidence intervals $(\mathrm{CI})$, where appropriate. 
Also, we reported the median of antibody titers and the interquartile ranges (IQR). A stepwise backward logistic regression model was constructed. The coefficients of the logistic regression model were used to measure the associations of independent variables with the protective level of anti-VZV. A variable could be entered into the model if the level of significance (F-value) was less than 0.05 and removed if it was greater than 0.10 . The level of agreement between self-reported history and seroprevalence (serological results) was determined by kappa statistic. Sensitivity, specificity, positive predictive value (PPV) and negative predictive value (NPV) of the recalled history were also calculated by Open-epi software [20]. Probability (p) values lower than 0.05 were considered significant using 2-sided comparisons. Statistical analyses were conducted using the Statistical Package for Social Sciences (SPSS) for Windows, version 19.0 (Chicago, IL, USA).

\section{Definition of terms}

In our study, family size was defined as the number of inhabitants per house, sensitivity as the ability of finding immune cases based on a positive answer on their historical enquiry, specificity as the ability of finding subjects susceptible to VZV based on a negative answer, positive predictive value (PPV) as the probability of being immune to VZV (confirmed by serology) when we have a "yes" answer to the historical enquiry, and negative predictive value (NPV) as the probability of being prone to VZV when we have a "no" answer.

The likelihood ratio (LR) is used to assess how good a diagnostic test is and to help in selecting an appropriate diagnostic test(s) or sequence of tests. They have advantages over sensitivity and specificity because they are less likely to change with the prevalence of the disorder. In this study, we defined positive LR as the likelihood of having immunity to VZV when self-reported history of Varicella was positive (in comparison with the lack of immunity when the report was positive). This could be shown as "sensitivity/1-specificity". Also, negative LR was defined as the likelihood of having immunity when the history was negative (in comparison with the lack of immunity when the report was negative) and it could be described as "1-sensitivity/specificity" [21].

And finally, Cohen's kappa measures the agreement between the evaluations of two tests when both are rating the same object. The value of " 1 " indicates perfect agreement, while the value of " 0 " indicates that agreement is no better than chance.

\section{RESULTS}

The response rate was more than 94\% (255/270). All 255 participants were students of medical sciences, with a mean age of $21.3 \pm 4.3$ years (range: $18-49$ ). More than $1 / 3$ of the participants $(37.6 \%, \mathrm{~N}=96)$ were students of medicine, while $32.2 \%(\mathrm{~N}=82)$ and $30.2 \%$ $(\mathrm{N}=77)$ were nursing and obstetrics students, respectively. In our study, $73.7 \%$ of the participants were female (Table 1). The mean age of students with positive protective result was 21.59 years (95\% confidence interval (CI): 20.91-22.27), while students with negative result had the mean age of 20.46 years (95\% CI: 19.82-21.09). No significant difference regarding age was observed between the groups ( $\mathrm{p}$-value $=0.06$ ).

The seropositivity rate was $74.5 \%$ (95\% CI: 68.9-79.6) based on 255 assayed samples by ELISA serology tests. We considered 3 equivocal results as negative because the students will work in the occupational health care setting. According to the results of serological tests, median antibody titer obtained among seropositive participants was $157 \mathrm{U} / \mathrm{ml}(\mathrm{IQR}=10-301)$. Medical students had the lowest seropositivity $(65.6 \%)$ with median antibody titer (116 U/m/l, IQR = 0.2-307), followed by obstetrics $75.3 \%$ seropositivity with median antibody titer $(185 \mathrm{U} / \mathrm{ml}$, IQR = 8-286), and nursing $84.1 \%$ seropositivity with median antibody titer $(171 \mathrm{U} / \mathrm{ml}, \mathrm{IQR}=31-306)$. 
Table 1. Distribution of Varicella immunity among different characteristics of students

\begin{tabular}{|c|c|c|c|c|c|c|c|}
\hline \multirow{3}{*}{ Characteristics } & \multicolumn{6}{|c|}{ Titer of Varicella zoster antibody } & \multirow{3}{*}{$\begin{array}{c}\mathrm{p} \\
\left(\mathrm{Chi}^{2}\right)\end{array}$} \\
\hline & \multicolumn{2}{|c|}{ positive } & \multicolumn{2}{|c|}{ negative } & \multicolumn{2}{|c|}{ total } & \\
\hline & $\mathrm{n}$ & $\%$ & $\mathrm{n}$ & $\%$ & $\mathrm{n}$ & $\%$ & \\
\hline Sex & & & & & & & 0.725 \\
\hline male & 51 & 26.8 & 16 & 24.6 & 67 & 26.3 & \\
\hline female & 139 & 73.2 & 49 & 75.4 & 188 & 73.7 & \\
\hline Discipline of study & & & & & & & $0.018^{*}$ \\
\hline medicine & 63 & 33.2 & 33 & 50.8 & 96 & 37.6 & \\
\hline nursing & 69 & 36.3 & 13 & 20.0 & 82 & 32.2 & \\
\hline obstetrics & 58 & 30.5 & 19 & 29.2 & 77 & 30.2 & \\
\hline Marital status & & & & & & & $0.012^{*}$ \\
\hline single & 162 & 85.3 & 63 & 96.9 & 225 & 88.2 & \\
\hline married & 28 & 14.7 & 2 & 3.1 & 30 & 11.8 & \\
\hline Family members (n) & & & & & & & $0.008^{*}$ \\
\hline $3-4$ & 53 & 31.7 & 32 & 52.5 & 85 & 37.3 & \\
\hline $5-6$ & 76 & 45.5 & 23 & 37.7 & 99 & 43.4 & \\
\hline$\geq 7$ & 38 & 22.8 & 6 & 9.8 & 44 & 19.3 & \\
\hline Smoking & & & & & & & 0.881 \\
\hline no & 182 & 95.8 & 63 & 96.9 & 245 & 96.1 & \\
\hline yes & 5 & 2.6 & 1 & 1.5 & 6 & 2.4 & \\
\hline blank & 3 & 1.6 & 1 & 1.5 & 4 & 1.6 & \\
\hline Acquisition history & & & & & & & $<0.001^{*}$ \\
\hline no & 31 & 16.3 & 43 & 66.2 & 74 & 29.0 & \\
\hline yes & 132 & 69.5 & 13 & 20.0 & 145 & 56.9 & \\
\hline can't remember & 27 & 14.2 & 9 & 13.8 & 36 & 14.1 & \\
\hline
\end{tabular}

* The $\mathrm{Chi}^{2}$ statistic is significant at the level of 0.05 .

Although nursing students had a better VZV immunity status than other students in the preliminary analysis, the binary logistic regression did not confirm this difference. Students with small family size (3-4 people) had the lowest seropositivity with $62.4 \%$, followed by those with medium family size (5-6 people) with $76.8 \%$, and students with large family size ( $\geq 7$ people) with $86.4 \%$. The differences were significant between the groups $(p=0.008)$. To assess predicting factors as regards the positive protective result, we used a binary logistic regression model. The variables included the marital status, number of family members, study discipline and acquired VZV history. After a stepwise backward analysis, only the number of family members, and acquired VZV history remained in the model (Table 2).

Table 3 shows the recalled history of Varicella versus serology. Among all seropositive participants, $69.5 \%$ gave a history of Varicella infection, while none had a history of vaccination. As shown in Table 1, 61.5\% of medical, 51.2\% of nursing, and $57.1 \%$ of obstetrics students (overall $57 \%$ of participants) reported a history of Varicella, and there 
Table 2. Independent variables associated with the protective level of anti-Varicella situation (final logistic regression model)*

\begin{tabular}{|c|c|c|c|c|}
\hline \multirow{2}{*}{ Variables } & \multirow{2}{*}{$\mathrm{p}$} & \multirow{2}{*}{$\beta$} & \multicolumn{2}{|c|}{$95 \%$ CI for $\beta$} \\
\hline & & & lower & upper \\
\hline Number of family members & 0.008 & 0.701 & 0.539 & 0.911 \\
\hline Acquisition history & $<0.001$ & 0.186 & 0.099 & 0.351 \\
\hline Constant & 0.007 & 7.276 & & \\
\hline
\end{tabular}

* Variables entered in step 1: marital status, discipline of study, family size and acquisition history.

$\beta$ - regression coefficient; $\mathrm{CI}$ - confidence interval.

was no significant statistical difference between them. Only one person had a history of zoster. The overall PPV for serologic immunity given a history of chicken pox was $91 \%$ (Table 3). NPV for the lack of serologic immunity given a negative history of chicken pox was $58.1 \%$. The NPV of a history of chicken pox for serologic immunity was significantly lower in nursing students (25\%; 95\% CI: 14.2-40.2) than in obstetrics (51.5\%; 95\% CI: 35.2-67.5) and medical students (67.6\%; 95\% CI: 51.5-80.4).

The overall sensitivity of recalled history for serologic immunity was $69.5 \%$ (95\% CI: 62.6-75.6) and it was lower amongst nursing students (56.5\%; 95\% CI: 44.8-67.6), when compared to obstetrics $(72.4 \%$; $95 \%$ CI: 59.8-82.2) and medical students (80.9\%; 95\% CI: 69.6-88.7). The overall specificity of recalled history for serologic immunity was $80 \%$ (95\% CI: 68.7-87.9). It was lower in medical students (75.8\%; 95\% CI: 59.0-87.2) than in nursing (76.9\%; 95\% CI: 49.7-91.8) and obstetrics students (89.5\%; 95\% CI: 68.6-97.0). The kappa statistic for the overall level of agreement between self-reported history and seroprevalence was 0.40 (95\% CI: $0.28-0.51)(\mathrm{p}<0.01)$ with a lower percentage in nursing students (0.18; 95\% CI: 0.02-0.34), compared to obstetrics $(0.49$; $95 \%$ CI: $0.29-0.70)$ and medical students $(0.55 ; 95 \%$ CI: $0.35-0.75)$. The results of the likelihood ratio, diagnostic odds and accuracy calculations have also been provided in Table 3 .

Table 3. Specifications and values of recalled history of VZV as a test for finding immune cases

\begin{tabular}{lcccccccc}
\hline & \multicolumn{3}{c}{ Medical } & \multicolumn{2}{c}{ Nursing } & \multicolumn{2}{c}{ Obstetrics } & \multicolumn{2}{c}{ Total } \\
\cline { 2 - 8 } \multicolumn{1}{c}{ Variables } & $\begin{array}{c}\text { estimate } \\
(\%)\end{array}$ & $95 \% \mathrm{CI}$ & $\begin{array}{c}\text { estimate } \\
(\%)\end{array}$ & $95 \% \mathrm{CI}$ & $\begin{array}{c}\text { estimate } \\
(\%)\end{array}$ & $95 \%$ CI & $\begin{array}{c}\text { estimate } \\
(\%)\end{array}$ & $95 \%$ CI \\
\hline Sensitivity & 80.90 & $69.6-88.7$ & 56.50 & $44.8-67.6$ & 72.40 & $59.8-82.2$ & 69.50 & $62.6-75.6$ \\
Specificity & 75.80 & $59.0-87.2$ & 76.90 & $49.7-91.8$ & 89.50 & $68.6-97.0$ & 80.00 & $68.7-87.9$ \\
PPV & 86.40 & $75.5-93.0$ & 92.90 & $81.0-97.5$ & 95.40 & $84.8-98.7$ & 91.00 & $85.3-94.7$ \\
NPV & 67.60 & $51.5-80.4$ & 25.00 & $14.2-40.2$ & 51.50 & $35.2-67.5$ & 47.30 & $38.2-56.5$ \\
Diagnostic accuracy & 79.20 & $70.0-86.1$ & 59.80 & $48.9-69.7$ & 76.62 & $66.0-84.7$ & 72.20 & $66.4-77.3$ \\
Positive LR & 3.34 & $2.6-4.3$ & 2.45 & $1.2-4.9$ & 6.88 & $2.5-18.7$ & 3.47 & $3.0-4.0$ \\
Negative LR & 0.25 & $0.2-0.3$ & 0.56 & $0.5-0.6$ & 0.31 & $0.3-0.4$ & 0.38 & $0.36-0.40$ \\
Diagnostic odds & 13.28 & $4.8-36.6$ & 4.33 & $1.1-17.1$ & 22.30 & $4.6-107.7$ & 9.10 & $4.60-18.0$ \\
Cohen's kappa & 0.55 & $0.35-0.75$ & 0.18 & $0.02-0.34$ & 0.49 & $0.29-0.70$ & 0.40 & $0.28-0.51$ \\
(unweighted) & & & & & & & & \\
\hline
\end{tabular}

PPV - positive predictive value; NPV - negative predictive value; LR - likelihood ratio.

$\mathrm{CI}$ - confidence interval. 


\section{DISCUSSION}

Different studies have been conducted on various Iranian populations over the past several years to investigate protection against VZV [11-16,22-24]. The results of this study are important to determine the ongoing VZV protection status and choose a strategy for medical students' vaccination. In Iranian medical universities, all obstetrics and the majority of nursing students are female. Similarly in our study, the majority of participants were female. The overall seroprevalence of Varicella was $74.5 \%$. This is among the lowest rates reported from other countries so far [7,8-10]. Similar recent studies from different regions of Iran reported various results. Our findings are compatible with a 2012 study of 313 adults (aged 20-40 years) from Tehran that showed $78 \%$ seropositivity to Varicella [11].

A study from Hamadan (western Iran) and another from Babol (northern Iran) revealed that respectively 78.4\% and $90.2 \%$ of pregnant women were immune to Varicella $[14,15]$. Another study from Jahrom, southern Iran, showed that $72.7 \%$ of young women were immune to Varicella before their marriage [16]. This diversity in findings may have resulted from different climates in various regions of our country (the north of Iran is a part of Mediterranean climate while the south has a tropical climate). Because of lower Varicella exposure in childhood and consequent higher susceptibility in adulthood, Varicella occurs more frequently in adults who reside in tropical regions than in those in other geographic areas [25,26].

For example, in some reports from developed European countries (e.g. Germany and Switzerland), the seroprevalence of Varicella among medical students was larger than in our study, even though their participants did not have a history of vaccination in the neonatal period [27,28]. In other words, none of the 170 students in the Swiss study had received any immunization against VZV, but still 144 (97\%) of 149 individuals were seropositive.

Only two studies from Kermanshah (west of Iran) and Tehran (the capital of Iran) reported VZV seroprevalence among students of medical sciences $(84.5 \%$ and $80 \%$, respectively), but they had a limited number of participants (62 and 35 students, respectively) [18,19]. According to the previous reports from Iran, in 2003, seropositivity of 20-24-year-olds equaled $88 \%$ and it decreased to $74.5 \%$ in our study [13]. Therefore, we may conclude the occurrence of a little decline in the incidence of Varicella in Iranian young adults over the past decade. The relative decrease in the prevalence of immunity in younger age groups could be a result of recent reduction in exposure to the virus in the Iranian community related to smaller family size and modernization trend [2]. Although the majority of VZV infections occur during early childhood, some epidemiological evidence from temperate areas shows an upward shift in the age distribution of Varicella [29]. This shift has potentially important consequences on morbidity and mortality of health workers (especially pregnant women). A similar changing pattern may occur in our country and further studies are required to prove it.

In addition, we examined the relationship between family size and anti-VZV results. In our study, anti-VZV positivity had a significant direct association with large family size (as an indicator of crowding), which is in agreement with other reports [30]. These studies have shown that the risk of becoming infected with VZV is largely determined by the frequency and duration of exposure to airborne droplet nuclei in poorly ventilated indoor settings. This is a well-recognized pattern for several communicable infections such as mycobacterium tuberculosis infection (TB) and measles. Another study from the Qazvin province that assessed the influence of household crowding on the tuberculin skin test (TST) result - reported a significant direct association [31].

In fact, the route of transmission in pulmonary TB, measles, Varicella, or disseminated zoster is similar (droplet nuclei [particles smaller than $5 \mu \mathrm{m}$ ] or dust particles containing the infectious agent) [32]. These particles can 
remain suspended in the air and travel long distances. Inhalation of such particles may result in developing infection in a susceptible host, so airborne precautions are indicated for documented or suspected patients.

In our study, there was no association between seropositivity and age, which has been found by other investigators $[12,13]$. In the above-mentioned studies, a rapid increase in seropositivity occurred until the age of 20 , while almost all students in our study were more than 20 years old. In other words, the range of age in the participants of our study was too narrow to let us find a significant relationship between age and seroprevalence. Similarly to other investigations, we did not find an association between sex and prevalence of VZV antibodies [2]. Although in our study nursing students had a better VZV immune status than other students in the preliminary analysis, this association was not confirmed in the final analysis. More studies are needed to determine other affecting factors.

In this study, the overall PPV of reported history for serological immunity among students (91\%) was comparable to another study that had already documented an average PPV of 95\% amongst Iranian adults (20-40 years old) [11]. This high rate of PPV means that we may rely on a positive result of the test (recall of disease occurrence). Several studies from other countries have also shown a reliable estimate for seroprevalence of infection through self-reported history $[33,34]$. Lower NPV than PPV may be attributable to early Varicella affection in the majority of participants. NPV noted in this study $(58.1 \%)$ was higher than in other reports, where NPV ranged from $6 \%$ to $44 \%[35,36]$. An explanation could be the younger age of our study participants and their education level (as shown by other studies, NPV is higher in younger people) [35].

Another explanation for lower NPV in some studies is the route of data gathering [37]. While most studies obtained their data of history only through a self-administered questionnaire, we gathered more information by an additional interview with the participants. Altogether, high PPV of recall for previous chickenpox indicates that positive history can reliably distinguish immunized from non-immunized people, and thus students with history of Varicella infection could be excluded from serologic screening, but negative history should be interpreted cautiously because of relatively low NPV.

\section{Limitations}

This study had few limitations. In our study, nursing students showed lower positive LR, diagnostic odds and Cohen's kappa than other students, while their negative LR was higher. Although the differences in PLR and NLR could be attributable to diversity of sensitivity and specificity of 3 groups, it is not easy to find a reason for other discrepancies. The differences in the personal or familial background may be a potential reason.

Despite remarkable results, generalizability of findings (regarding the whole population of students) is not quite possible. Since the entrance university exam in Iran is a nationwide competitive test, we expected to have a random geographical pattern for students' admission. However, the participants were mostly based in the Tehran and Qazvin provinces, which could make a systematic difference between them and the students from other universities and provinces (a potential source for low generalizability). Finally, the causative inference of the found relationships should be interpreted cautiously due to the design of this study (cross-sectional).

\section{CONCLUSIONS}

At the moment, the prevalence of Varicella antibodies in students of medical sciences is high and therefore the overall occupational risk of VZV infection for students at risk is low. Nevertheless, immunization of medical students - who have never been contacted Varicella cases will be logical in the near future (due to a decline in the 
incidence of Varicella in Iranian young adults over the past decade). Of course, further studies are required to evaluate the cost-benefit ratio of a selective vaccination program for students of medical sciences in Iran (particularly females). Negative reported history did not indicate Varicella susceptibility of medical sciences students; hence as mentioned in similar studies, all medical sciences students should be tested for Varicella immunity regardless of the history of previous infection [38,39]. To avoid virus transmission from students to patients and potential complications of Varicella, especially in pregnant women, we recommend serologic tests in obstetrics students who have never been in contact with suspected or proven cases of Varicella. Until VZV vaccine is accessible in Iran, preventive care is recommended for cases without immunity to Varicella-zoster virus.

\section{ACKNOWLEDGEMENTS}

We thank Ms. Khadive and Ms. Zakilou for sampling the study participants. We would also like to thank all participants (students of the Qazvin University of Medical Sciences) for their cooperation and dedication to the study.

\section{REFERENCES}

1. Heininger U, Seward JF. Varicella. Lancet. 2006;368(9544): 1365-76, http://dx.doi.org/10.1016/S0140-6736(06)69561-5.

2. Whitley RJ. Varicella-Zoster virus. In: Mandell GL, Bennett JE, Dolin R, editors. Mandell, Douglas, and Bennett's, Principles and practice of infectious diseases. $7 \mathrm{nd}$ ed. Philadelphia: Elsevier Churchill Livingstone Press; 2010. p. 1963-9.

3. Liese JG, Grote V, Rosenfeld E, Fischer R, Belohradsky BH, von Kries R, et al. The burden of Varicella complications before the introduction of routine Varicella vaccination in Germany. Pediatr Infect Dis J. 2008;27(2):119-24, http://dx.doi. org/10.1097/INF.0b013e3181586665.
4. Persson A, Bergström T, Lindh M, Namvar L, Studahl M. Varicella-zoster virus CNS disease-Viral load, clinical manifestations and sequels. J Clin Virol. 2009;46(3):249-53, http://dx.doi.org/10.1016/j.jcv.2009.07.014.

5. Deborah E. McCarter-Spaulding. Varicella infection in pregnancy. JOGNN. 2001;30:667-73, http://dx.doi.org/10.1111/ j.1552-6909.2001.tb00014.x.

6. Almuneef M, Dillon J, Abbas MF, Memish Z. Varicella zoster virus immunity in multinational health care workers of a Saudi Arabian hospital. Am J Infect Control. 2003;31(6):375-81, http://dx.doi.org/10.1016/S0196-6553(02)48204-1.

7. Apisarnthanarak A, Kitphati R, Tawatsupha P, Thongphubeth K, Apisarnthanarak P, Mundy LM, et al. Outbreak of Varicella-zoster virus infection among Thai healthcare workers. Infect Control Hosp Epidemiol. 2007;28(4):430-4, http://dx.doi.org/10.1086/512639.

8. Wu MF, Yang YW, Lin WY, Chang CY, Soon MS, Liu CE. Varicella zoster virus infection among healthcare workers in Taiwan: Seroprevalence and predictive value of history of Varicella infection. J Hosp Infect. 2012;80(2):162-7, http:// dx.doi.org/10.1016/S0196-6553(02)48204-1.

9. Sam IC, Tariman H, Chan YF, Bador MK, Yusof MY, Hassan H. Varicella-zoster virus seroprevalence in healthcare workers in Kuala Lumpur, Malaysia. Med J Malaysia. 2008;63(5):429-30.

10. Holmes CN. Review Predictive value of a history of Varicella infection. Can Fam Physician. 2005;51(1):60-5.

11. Talebi Taher M, Rezaie O. Seroepidemiology of VZV in the young adults referring to Rasoul-Akram Hospital in Tehran. Sci J Kurdistan Univ Med Sci. 2012;17(1):36-42.

12. Ziyaeyan M, Alborzi A, Jamalidoust M, Moieni M, Pourabbas B. Seroepidemiology of Varicella zoster virus infection among 1-70 year individuals in Iran. Iran Red Crescent Med J. 2012;12(2):176-80.

13. Sharifi Z, Emadi Ghanjin S. The seroepidemiology of Varicella zoster (VZV) in different age groups in Tehran, Iran. Iran J Allergy Asthma Immunol. 2005;4(2):95-8.

14. Mamani M, Zamani M, Hashemi SH, Akhtari M, Niayesh A. Seroepidemiology of Varicella zoster virus 
among pregnant women in Hamedan, Iran. Afr J Microbiol Res. 2012;6(8):1829-32.

15. Bayani M, Siadati S, Esmaeilzadeh S, Asgari S, Salmani S. Seroprevalence of Varicella zoster antibodies among pregnant women in Babol, Northern Iran. Iran J Pathol. 2013;8(3):171-7.

16. Pourahmad M, Davami MH, Sotoodeh-Jahromi AR. Evaluation of anti-Varicella antibody in young women before their marriage: A sero-epidemiologic study in Iran. J Clin Virol. 2010;48(4):260-3, http://dx.doi.org/10.1016/j.jcv.2010.04.015.

17. Hosseininasab A, Arabzadeh A, Haghdoost AA, Helmi Z. Immunity against Varicella zoster virus based on history of previous chickenpox: A study in premarital Iranian women. Int J Infect Dis. 2013;17(7):e568-9, http://dx.doi.org/10.1016/ j.ijid.2013.01.033.

18. Farshchi A, Niayesh A. Seroprevalence of Varicella antibodies in healthcare workers in Imam Reza Hospital of Kermanshah-Iran. J Pharma \& Health Sci. 2012;1(1):37-40.

19. Pourakbari B, Shahbaznezhad L, Parvaneh N, Nikkhah S, Mahmoudi S, Teymuri M, et al. Seroepidemiology of Varicella zoster virus among children, adolescents and medical students in a referral children medical center, Tehran, Iran. Iran J Microbiol. 2012;4(3):136-8.

20. Dean AG, Sullivan KM, Soe MM. OpenEpi: Open Source Epidemiologic Statistics for Public Health [Internet]. Version 3.1. Atlanta: Rollins School of Public Health, Emory University; 2013 [updated 2013 Apr 6; cited 2013 Aug 2]. Available from: http://www.openepi.com.

21. Centre for Evidence-based Medicine at the University of Oxford (CEBM) Likelihood Ratios [cited 2013 Aug 1]. Available from: http://www.cebm.net/?o=1158.

22. Talebi-Taher M, Noori M, Shamshiri AR, Barati M. Varicella zoster antibodies among health care workers in a university hospital, Teheran, Iran. Int J Occup Med Environ Health. 2010;23(1):27-32, http://dx.doi.org/10.2478/v10001010-0011-x.

23. Motamedifar M, Handjani F, Hadi N, Shahkarami MK, Mehrabani D. Seroprevalence of Varicella-zoster virus in children from Shiraz-Iran. Iran J Immunol. 2006;3(1):43-6.
24. Ehsanipour F, Shayanfar N, Salariyan K. Surveying of protective antibody against Varicella zoster virus (VZV) infection in children referring to Hazrat-e-Rasool Akram Hospital 2005. Iran Uni Med Sci J. 2009;16(64):38-44.

25. Hambleton S, Gershon AA. Preventing Varicella-zoster disease. Clin Microbiol Rev. 2005;18:70-80, http://dx.doi. org/10.1128/CMR.18.1.70-80.2005.

26. Richard VS, John TJ, Kenneth J, Richard VS, John TJ, Kenneth J, et al. Should health care workers in the tropics be immunized against Varicella? J Hosp Infect. 2001;47(3):243-5, http://dx.doi.org/10.1053/jhin.2000.0855.

27. Baer G, Bonhoeffer J, Schaad UB, Heininger U. Seroprevalence and immunization history of selected vaccine preventable diseases in medical students. Vaccine. 2005;23(16):2016-20, http://dx.doi.org/10.1016/j. vaccine.2004.03.073.

28. Wicker S, Rabenau HF, Gottschalk R, Doerr HW, Allwinn R. Seroprevalence of vaccine preventable and bloodtransmissible viral infections (measles, mumps, rubella, polio, HBV, HCV and HIV) in medical students. Med Microbiol Immunol. 2007;196(3):145-50, http://dx.doi.org/10.1007/ s00430-007-0036-3.

29. Uduman SA, Tahira AM, Al-Wash R, Usmani MA, Bener A. Varicella susceptibility among children and healthy adults in the United Arab Emirates. East Mediterr Health J. 2001; 7(4-5):604-8.

30. Nichols RA, Averbeck KT, Poulsen AG, Al Bassam MM, Cabral F, Aaby P, et al. Household size is critical to Varicella-zoster virus transmission in the tropics despite lower viral infectivity. Epidemics. 2011;3(1):12-8, http://dx.doi. org/10.1016/j.epidem.2010.11.003.

31. Allami A, Mohammadi N, Afaghi A, Lashgari A. BCG Scar formation and test results in two generations. Shiraz E Med J. 2011 [cited 2014 Feb 24];12(1): [about 8 p.]. Available from: http://semj.sums.ac.ir/vol12/ jan2011/89036.pdf.

32. Siegel JD, Rhinehart E, Jackson M, Chiarello L. 2007 Guideline for isolation precautions: preventing transmission 
of infectious agents in health care settings. Am J Infect Control. 2007;35(10):S65-S164, http://dx.doi.org/10.1016/ j.ajic.2007.10.007.

33. Banz K, Wagenpfeil S, Neiss A, Goertz A, Staginnus U, Vollmar J, et al. The cost-effectiveness of routine childhood Varicella vaccination in Germany. Vaccine. 2003;21(11):1256-67, http://dx.doi.org/10.1016/S0264-410X (02)00431-0.

34. Alagappan K, Fu L, Strater S, Atreidis V, Auerbach C. Seroprevalence of Varicella antibodies among new house officers. Ann Emerg Med. 1999;33(5):516-9.

35. Coyle PV, McCaughey C, Wyatt DE, O’Neill HJ. Varicella vaccine in pregnancy. Testing should be offered to women without a history of chickenpox. Br Med J. 1997;314(7075): 226, http://dx.doi.org/10.1136/bmj.314.7075.226.
36. Burnham BR, Wells TS, Riddle JR. A cost-benefit analysis of a routine Varicella vaccination program for United States Air Force Academy cadets. Mil Med. 1998;163(9):631-4.

37. Dashraath P, Ong E-S, Lee VJ. Seroepidemiology of Varicella and the reliability of a self-reported history of Varicella infection in Singapore military recruits. Ann Acad Med Singapore. 2007;36(8):636-41.

38. Almuneef M, Memish ZA, Abbas MF, Balkhy HH. Screening healthcare workers for Varicella zoster virus: Can we trust the history? Infect Control Hosp Epidemiol. 2004;25(7):595-8, http://dx.doi.org/10.1086/502445.

39. Baer G, Bonhoeffer J, Schaad UB, Heininger U. Seroprevalence and immunization history of selected vaccine preventable diseases in medical students. Vaccine. 2005;23(16): 2016-20, http://dx.doi.org/10.1016/j.vaccine.2004.03.073.

This work is available in Open Access model and licensed under a Creative Commons Attribution-NonCommercial 3.0 Poland License - http://creativecommons.org/ licenses/by-nc/3.0/pl/deed.en. 